\title{
On fractional order models for Hepatitis C
}

\author{
E Ahmed $^{1 *}$, H A El-Saka ${ }^{2}$
}

\begin{abstract}
In this paper we present a fractional order generalization of Perelson et al. basic hepatitis $\mathrm{C}$ virus (HCV) model including an immune response term. We argue that fractional order equations are more suitable than integer order ones in modeling complex systems which include biological systems. The model is presented and discussed. Also we argue that the added immune response term represents some basic properties of the immune system and that it should be included to study longer term behavior of the disease.
\end{abstract}

\section{Introduction}

Hepatitis $C$ is one of many serious infectious diseases affecting humans. An estimated about 170 million people worldwide are infected with hepatitis C. No vaccine against hepatitis $\mathrm{C}$ is available. Egypt has the highest rate of infections by hepatitis C virus (HCV) genotype 4. Chronic HCV infection is the main cause leading to liver transplant or death [1]. Antiviral therapy has been used to treat chronically HCV infected patients. Relatively successful treatment contains pegylated interferon (PEGIFN) and ribavirin (RBV). Typical response ate biphasic beginning with rapid viral decline phase followed by slower decline phase. Sometimes there is more complicated behavior but they will not be discussed here. Extensive and impressive studies have been done by Perelson and his group [2-5]. Here we present a fractional order generalization of a basic HCV model [2] including the immune response (Ir) term proposed in [3].

In sec. 2 we argue that fractional order equations are more suitable than integer order ones in modeling complex systems which include biological systems. In sec. 3 the model is presented and discussed. Also we argue that the added immune response term represents some basic properties of the immune system and that it should be included to study longer term behavior of the disease.

\section{Fractional Equations}

Caputo's definition for derivative of order $0<\alpha \leq 1$ is given by [6]

\footnotetext{
* Correspondence: magd45@yahoo.com
${ }^{1}$ Mathematics Department, Faculty of Science, Mansoura University, 35516,

* Correspondence: magd45@yahoo.com
${ }^{1}$ Mathematics Department, Faculty of Science, Mansoura University, 35516, Mansoura, Egypt
} Mansoura, Egypt where $\Gamma(\alpha)$ is the Gamma function and $f(s)$ is the first derivative. It is known that FO is more suitable in describing complex adaptive systems e.g. biological systems since they naturally represent fractal, memory and non-locality effects [7-9].

\section{The model and conclusions}

The fractional order hepatitis $\mathrm{C}$ virus $(\mathrm{HCV})$ model is given by

$$
\begin{aligned}
& D^{\alpha} T=s-d T-(1-\eta) \beta V T, \\
& D^{\alpha} I=(1-\eta) \beta V T-\delta I\left(1-I / c_{2}\right), \\
& D^{\alpha} V=\left(1-\varepsilon_{p}\right) p I-c V,
\end{aligned}
$$

Where $0<\alpha \leq 1, T$ represents uninfected hepatocytes, $I$ represents infected hepatocytes and $V$ represents virus. The model assumes that uninfected hepatocytes are produced at a constant rate $s$, die at rate, $d$, per cell and are infected at constant rate $\beta$. Infected hepatocytes are lost at a rate $\delta$ per cell. Viral particles (virions) are produced at rate $p$ per infected hepatocyte and cleared at rate $c$ per virion. Chronic HCV infection is treated using interferon-a in combination with the antiviral drug ribavirin. Interferon-a acts primarily by blocking the production/ release of new virus, although we also allow for a treatment effect in blocking de novo infection. The efficacy of treatment in blocking virion production and reducing new infections are described by two parameters, $\varepsilon_{p}$ and $\eta$, respectively. For example, a treatment efficacy in 
blocking virion production of $95 \%$ corresponds to $\varepsilon_{p}=0.95$.

The approximate solutions displayed in Figs. 1, 2, 3 for different $\alpha$ and $s=2.6 \times 10^{4}, d=0.0026, \eta=0.95$, $\beta=2.25 \times 10^{-7}, \delta=0.26, c_{2}=5 \times 10^{6}, c=6.0$, $\varepsilon_{p}=0.99, p=2.9$
We have the following conclusions:

i) Mathematical models, when done by a group of mathematicians and HCV specialists give relevant results e.g. explaining the role of RBV [4], explaining the observed two phase decline hence deriving the
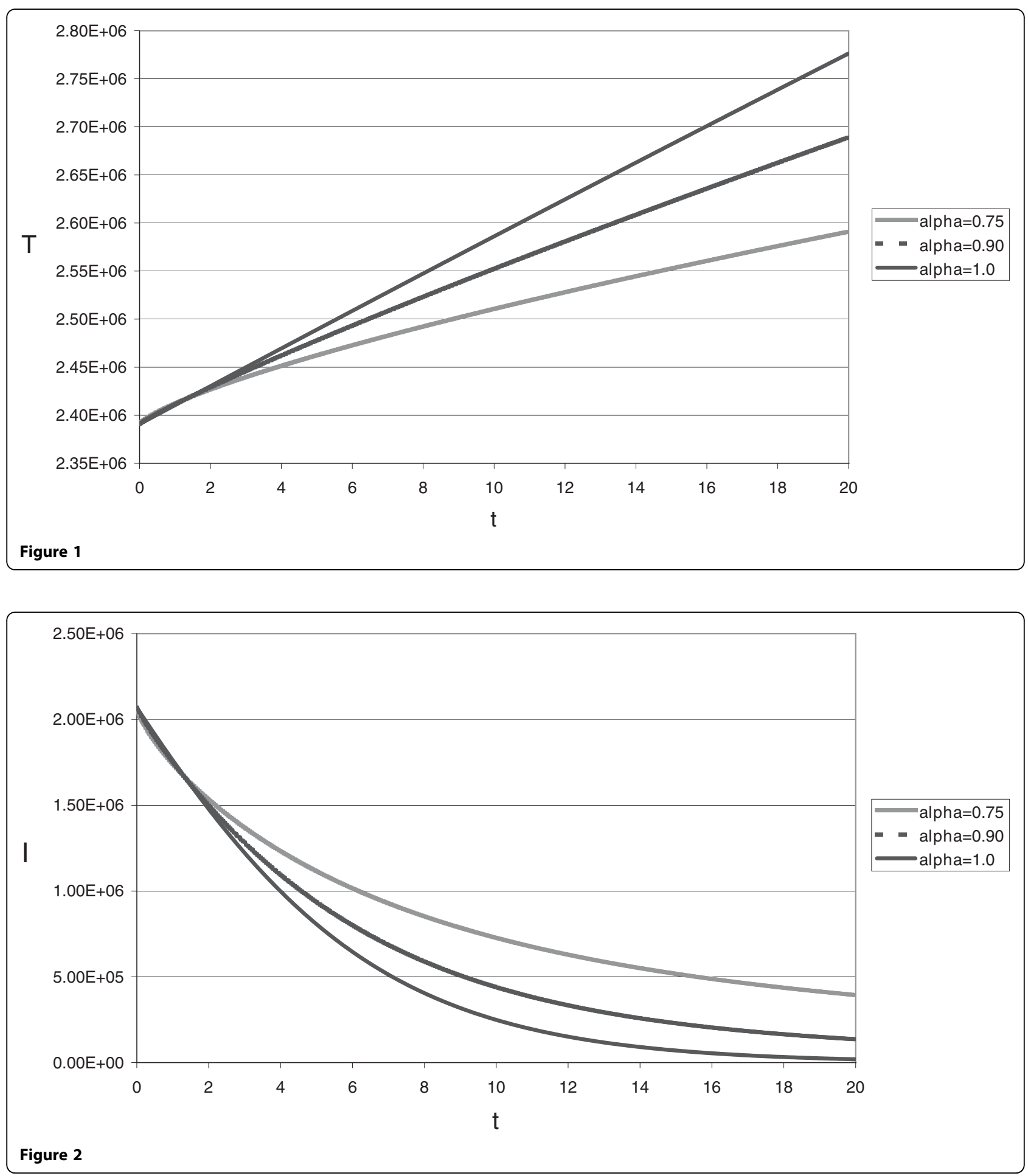


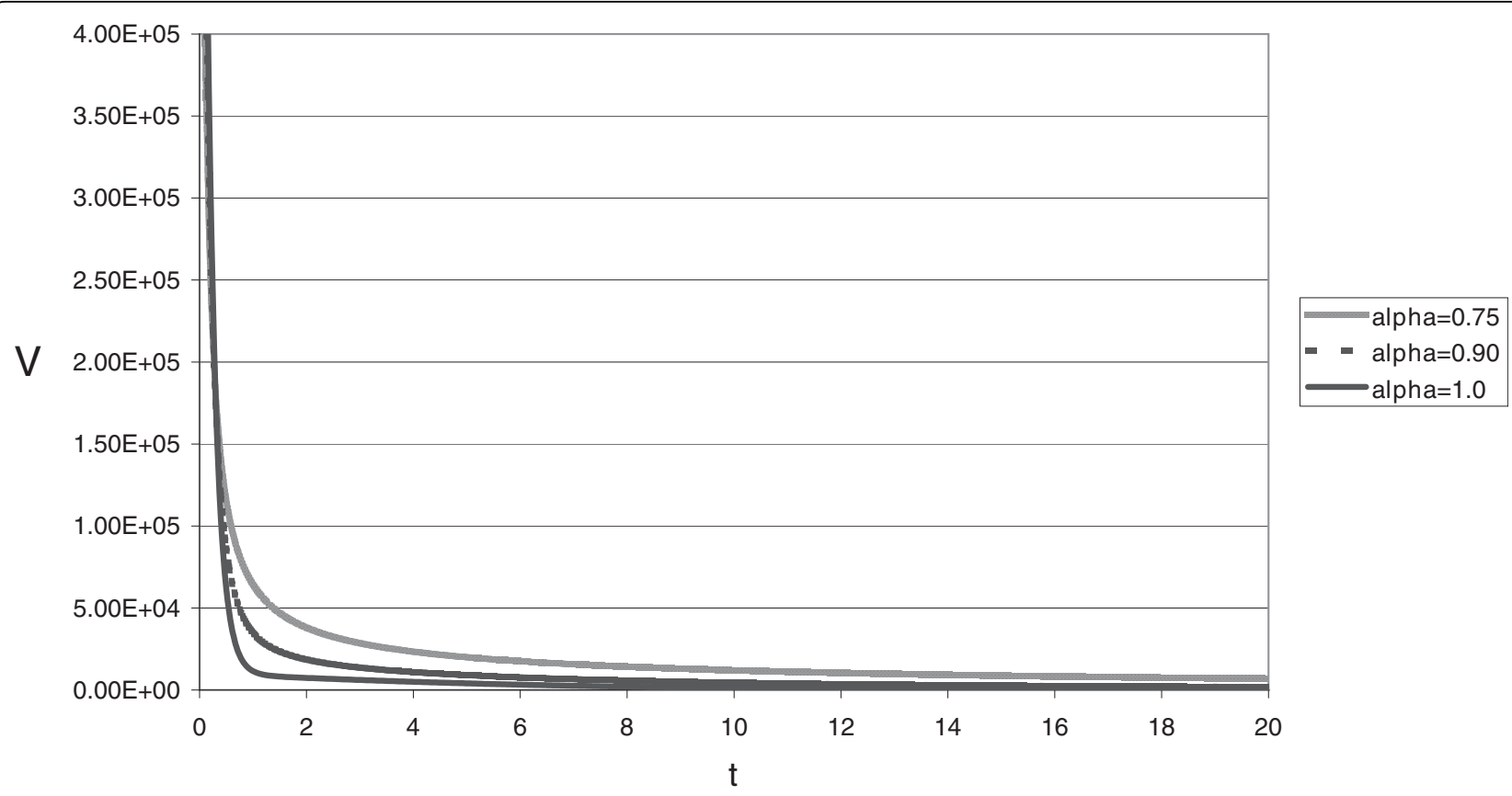

Figure 3

role of the drug in initially blocking the viral secretion more than blocking the cells' infection etc. [4]. ii) The term added in equation (1) represents the well known high and low zone tolerance of the immune response (There is no Ir if the antigen number is either too high or too low [10]) since it vanishes for both limits $I \rightarrow 0$ and $I \rightarrow c_{2}$. Immune response is significant for long time virus dynamics.

iii) Fractional order results show the realistic biphasic decline behavior of HCV but at a slower rate.

iv) Since multi-drugs are strongly recommended to avoid drug resistance it is proposed that a further drug should be used in addition to Peg-IFN and RBV. Notice that RBV may not be considered as independent drug since, when used alone, it has no effect on $\mathrm{HCV}$.

\section{Acknowledgements}

We thank Prof. A. S. Perelson for sending us copies of his work.

\section{Author details}

${ }^{1}$ Mathematics Department, Faculty of Science, Mansoura University, 35516, Mansoura, Egypt. ${ }^{2}$ Mathematics Department, Faculty of Science, Mansoura University, 34517, New Damietta, Egypt.

Received: 30 December 2009 Accepted: 18 March 2010 Published: 18 March 2010

\section{References}

1. Hepatitis C. [http://en.wikipedia.org/wiki/Hepatitis_C]

2. Dahari H, Lo A, Ribeiro RM, Perelson AS: Modeling hepatitis C virus dynamics: Liver regeneration and critical drug efficacy. J Theoret Biol 2007, 247:371-381.
3. Brunetto $M$, Colombatto $P$, Bonino F: Bio-mathematical models of viral dynamics to tailor antiviral therapy in chronic viral hepatitis. World J Gastroenterol 2009, 15:531-537.

4. Dahari H, Shudo E, Ribeiro RM, Perelson AS: Mathematical modeling of $\mathrm{HCV}$ infection and treatment. Hepatitis $\mathrm{C}$ methods and Protocols Humana Press, NJTang H, 2 2008, 439-453.

5. Dixit N, Layden-Almer J, Layden T, Perelson AS: Modeling how ribavirin improves interferon response rates in hepatitis $C$ virus infection. Nature 2004, 432:922-924.

6. Podlubny I: Fractional differential equations. Academic Press 1999.

7. Rocco A, West BJ: Fractional calculus and the evolution of fractal phenomena. Physica A 1999, 265:535-546.

8. Stanislavsky AA: Memory effects and macroscopic manifestation of randomness. Phys Rev 2000, E61:4752-4759.

9. Zahran MA, Abulwafa EM, El-wakil SA: Fractional Fokker-Planck equation on comb-like model. Physica A 2003, 323:237-248.

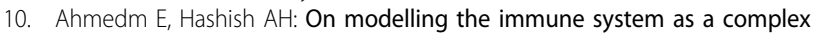
system. Theory in Biosciences 2006, 124:413-418.

doi:10.1186/1753-4631-4-1

Cite this article as: Ahmed and El-Saka: On fractional order models for Hepatitis C. Nonlinear Biomedical Physics 2010 4:1.

\section{Submit your next manuscript to BioMed Central and take full advantage of:}

- Convenient online submission

- Thorough peer review

- No space constraints or color figure charges

- Immediate publication on acceptance

- Inclusion in PubMed, CAS, Scopus and Google Scholar

- Research which is freely available for redistribution

Submit your manuscript at www.biomedcentral.com/submit 